\title{
L’Alguer, confí de confins
}

\author{
August Bover i Font
}

Universitat de Barcelona

\section{Resum}

L'article presenta el cas de l'Alguer (Sardenya) com a confí de la llengua catalana, enfront del sard i l'italià. Fa un repàs històric i exposa les relacions entre aquestes llengües, denuncia les actituds retrògrades que s'aprofiten d'aquestes situacions, i assenyala els instruments i els camins que permeten encara una certa possibilitat de supervivència.

Paraules clau: Alguer, Sardenya, català.

\section{Abstract}

The article presents the case for l'Alguer (Sardinia) as the border of the Catalan tongue as opposed to Sardinian and Catalan. It surveys and examines the history and relations between the two languages, denounces retrograde attitudes that take advantage of the current situation and describes the instruments and steps to be taken toward making their continued survival a possibility.

Key words: Alguer, Sardinia, Catalan.

Des del punt de vista lingüístic, podem considerar que Sardenya és el confí de l'expansió medieval catalana per la Mediterrània. La llarga estada dels catalans a l'illa — ara com ara molt més llarga que la dels italians, posem per cas-, lògicament, havia de tenir unes conseqüències lingüístiques. Per això, fora dels Països Catalans, Sardenya és l'únic territori on la presència de la llengua catalana és habitual en bona part de la documentació antiga i on una part de la toponímia, de l'antroponímia — hi són relativament freqüents els llinatges catalans més o menys deturpats- i del corpus lèxic de la llengua autòctona actual —especialment en el sard campidanès - tenen origen català; ${ }^{1}$ no és per casualitat, doncs, que fora de la forma original sarda alguns topònims majors, per exemple, només tinguin versió catalana i italiana: Càller / Cagliari.

1. Cfr. Jordi Carbonell i Francesco Manconi (dirs.), Els catalans a Sardenya, Barcelona: 1984, en català, o ID. I catalani in Sardegna, Cinisello Balsamo, 1984, en italià. 
Però, de l'antiga Sardenya urbana catalanoparlant, l'únic testimoni encara viu és la ciutat de l'Alguer. Si a la resta de Sardenya el català va anar retrocedint paulatinament - l'any 1724 Antoni de Bastero publicava la transcripció d'un passaport en llengua catalana estès a Càller només sis anys abans ${ }^{2}$-, no ho va fer —ni ho fa, tampoc, a l'Alguer actual- a favor del sard sinó del castellà, primer, i de l'italià, després. Si ens atenem als orígens, és facil d'entendre que hagi estat la Barceloneta sarda l'única població on s'ha mantingut la llengua catalana ja que, a diferència de les altres localitats de l'illa, l'Alguer va ser repoblada amb ciutadans de la Corona d'Aragó l'any 1372. Sens dubte, aquesta particular composició ètnica de la seva població li va permetre resistir lingüísticament, però sorprèn que a l'inici del segle XXI encara en poguem parlar com a realitat viva si tenim present com ha anat la història, és a dir, malgrat l'afebliment i posterior aniquilació de la Corona d'Aragó, malgrat l'afluència constant de població sarda, corsa o procedent de la Península Itàlica — del continent, que diuen a Sardenya - des de la fi del segle XV i, sobretot, malgrat les devastadores epidèmies de pesta que va patir els anys 1582-1583 i 1652. Només cal obrir la guia telefonica de la ciutat per adonar-se que els llinatges catalans que hi queden són comptadíssims, fenomen que no es dóna a Càller, per exemple, que en canvi avui és una ciutat totalment italianoparlant. Cosa que demostra que va ser precisament la població forana — sarda, bàsicament- que va fer seva la llengua, la que l'ha feta arribar fins als nostres dies. I aquesta resistència extraordinària ens porta encara a una segona i galdosa reflexió: sigui a l'Alguer o sigui al seu propi territori —els Països Catalans-, la llengua catalana continua caracteritzant-se no pas per ser una llengua que ha aconseguit una situació de normalitat en el seu territori — com per exemple l'alemany, l'espanyol, el francès o l'italià- sinó per ser una llengua difícil d'eradicar d'una manera total i definitiva. És a dir, continuem sent «fills de la morta-viva», que deia Constantí Llombart. ${ }^{3}$ No ens acabem de morir del tot. Però, fins quan?

Segurament molt més que en cap altre territori de llengua catalana, en el cas de l'Alguer, i si no hi ha canvis radicals i immediats, l'única resposta realista només pot ser: fins ben aviat. El municipi de l'Alguer és només un petit illot catalanoparlant en una illa sarda dins de l'oceà italià i, per tant, en la cruilla algueresa actualment hi conflueixen els confins de tres llengües: català, sard i italià.

Durant els anys setanta del segle XX, una bona part de la població autòctona va anar abandonant la transmissió familiar de la llengua catalana en favor de l'italià i en el darrer quart de segle s'hi va establir població sarda i italiana que no va tenir ni l'oportunitat ni l'interès d'aprendre l'alguerès (la variant local de la llengua catalana), totalment bandejat de l'ensenyament, dels mitjans de comunicació, de l'administració de justícia, de l'activitat laboral, etc., on sen-

2. Cfr. A. Bover i FonT, «La represa de les relacions culturals amb l'Alguer», Estudis de Llengua i Literatura Catalanes, II [= Homenatge a Josep M. de Casacuberta, 2], 1981, p. 410.

3. Los fills de la morta-viva, València: Impremta Emili Pasqual, 1879. Edició facsímil: València-Sueca: Edicions León Roca/Impremta Palàcios, 1973. 
yoreja l'italià, la llengua oficial de l'Estat. Un Estat, a més, que a diferència de l'espanyol o el francès mai no hi ha exercit la repressió lingüística directa - fet que acostuma a provocar la reacció dels oprimits — sinó que ha practicat magistralment el laissez faire, laissez passer. Senzillament, sense fer mai els passos necessaris per fer realitat el que diu la constitució italiana sobre aquest tema, ${ }^{4}$ s' ha anat aprofitant dels sovintejats errors dels sards i els algueresos.

Llevat d'una selecta minoria, fins ara des del costat sard no hi ha hagut una autèntica voluntat de recuperació de la llengua. Ja no hi van pensar a l'hora de redactar l'estatut d'autonomia, aprovat l'any 1947, per exemple. 5 A més, el fet que es tracti d'una llengua encara no unificada constitueix un obstacle fonamental que dificulta moltíssim qualsevol acció que es vulgui emprendre. I, no cal dir-ho, com sempre passa en aquests casos, cal esmerçar un munt de temps i d'energia a combatre els cantonalismes més estrets que sorgeixen arreu, sota la mirada complaguda — i, sovint, còmplice — de les autoritats de l'Estat i d'un ampli sector del funcionariat autòcton farcit d'autoodi.

En un marc així, ja es pot preveure que difícilment el català de l'Alguer pot tenir una situació envejable. Però, a més, i a diferència dels colons americans —anglòfons, francòfons, hispanòfons o lusòfons, tant se val-, que històricament van poder comptar sempre amb unes metròpolis potents, on la llengua autòctona no hi experimentava cap tipus de procés de minorització sinó tot el contrari -és cert que Portugal va començar a patir un procés de castellanització (1581-1640), però el va interrompre en aconseguir la independència-, els algueresos van patir, de Sardenya estant, la penetració castellana que va anar debilitant la Corona d'Aragó i, per tant, també els Països Catalans. L'aniquilació final de la Corona, a més, va trencar els vincles d'unió entre els diferents països que la integraven fins al punt que els catalans van arribar a perdre la memòria de les antigues colònies de Sardenya i no se'n van tornar a recordar fins que no es va iniciar el procés de reconstrucció nacional de la Renaixença, quan Manuel Milà i Fontanals li va encarregar a l'arqueòleg Francesc Martorell i Penya que aprofités el viatge que hi havia de fer per a l'estudi dels nuraghi per veure què en quedava de tot allò. ${ }^{6}$ Després va venir el consolat d'Eduard Toda, que va ser el gran difusor de la Sardenya catalana, fet que ja és prou conegut. ${ }^{7}$ Però la dictadura del general Primo de Rivera, la guerra d'Espanya, el feixisme italià, la Segona Guerra Mundial i la llarguíssima dictadura del general Franco van inhabilitar el segle XX per a la represa d'unes relacions normalitzades entre les dues comunitats catalanoparlants de l'una i l'altra banda del $\operatorname{mar}^{8}$ — si fem excepció, com sempre, d'unes petites elits. Per tant, la comu-

4. Cfr. A. Bover i FONT, «Literatura i models de llengua: algunes reflexions sobre el cas de l'Alguer», Llengua \& Literatura, n. 7, 1996, p. 326.

5. Cfr. Lorenzo Del Piano (a cura de), Lo Satuto Sardo, Sàsser: Della Torre, 1974.

6. Cfr. A. Bover i Font, La represa ..., op. cit., p. 410-412.

7. Cfr. Eufemià ForT i Cogul, Eduard Toda, tal com l'he conegut, Barcelona: Publicacions de l'Abadia de Montserrat, 1975, p. 79-96.

8. Cfr. Pere Català i RocA, «Vers el retrobament. Assaig d'interpretació històrica», Tramontane, n. 441-444 [= Retrobament de l'Alguer], gener-abril 1961, p. 5-32. 
nitat algueresa va quedar abandonada enmig del mar sense poder comptar amb el suport metropolità. Però, si no podia comptar amb l'ajut català, fins avui tampoc no ha pogut comptar amb l'ajut sard - ja he parlat abans de l'Alguer com a illa dins d'una illa. D'una banda, perquè històricament els sards han vist l'Alguer com una imposició exògena $i$, de l'altra, perquè pràcticament no han pogut ser mai amos a casa seva - no ens deixéssim enganyar per la minsa autonomia de què disposen des de 1947. Però ara, tants segles després, la catalanitat de l'Alguer ja forma part del patrimoni sard — com també en forma part el carlofortí, és a dir, el genovès arcaic parlat a la petita illa de Sant Pere, al sud de la costa de Ponent-, i el sard i el català hi pateixen els mateixos problemes. Sembla raonable pensar que convindria una ajuda mútua per tal de vèncer els obstacles. Això no obstant, sovint, quan des de l'Alguer s'ha demanat la protecció de la seva llengua, des de Càller s'ha contestat que no es podia donar a l'alguerès un tracte que encara no tenia el sard, calia fer cua darrere el sard, una cua aturada anys i panys a la portes tancades de Càller i de Roma, que no van entreobrir-se fins a 1997 (la llei sarda núm. 26 del 15 d'octubre: Promozione e valorizzazione della cultura e de la lingua della Sardegna) i 1999 (la llei italiana núm. 482 del 15 de desembre: Norme in materia di tutela delle minoranze linguistiche e storiche).

Ara bé, com acostuma a passar, tampoc a l'Alguer tots els problemes li vénen de l'exterior. Una altra de les diferències amb el cas americà és, evidentment, la de les dimensions. La llengua catalana a la Sardenya actual és només la llengua d'una petita ciutat, és una llengua municipal. ${ }^{9}$ I és ben sabut que, a tot arreu, els confins i les petites dimensions sovint són aprofitats pels elements més reaccionaris per aconseguir un cert protagonisme basat en l'autoodi. Lògicament, l'Alguer no és cap excepció a aquesta regla, són prou coneguts els episodis viscuts a començament del segle XX, en ocasió del Primer Congrés Internacional de la Llengua Catalana (Barcelona 1906).$^{10} \mathrm{I}$, pràcticament un segle després, en aquest sentit les coses no han canviat gaire. La voluntat d'aquest petit sector de convertir-se en l'únic interlocutor vàlid amb els Països Catalans i anihilar els qui tenen una visió oberta i cosmopolita, respectuosa amb la tradició local i els criteris científics i, per tant, del tot allunyada del seu sectarisme, troba un bon aliat en el desconeixement general català que, a vega-

9. L'any 2000, la ciutat comptava amb 43.109 habitants. No se'n tenen censos lingüístics i per això els càlculs s'han de basar en extrapolacions d'estudis parcials. L'any 1981, quan tenia 38.709 habitants, es calcula que els catalanoparlants eren el 46\%, és a dir, unes 18.000 persones. Extrec les dades de la Gran Enciclopèdia Catalana, 20 [= Cinquè suplement A-Z] Barcelona: Enciclopèdia Catalana, 2001, i de la pàgina web del Departament de Cultura de la Generalitat de Catalunya.

10. Cfr. A. Bover i Font, "Notícia de l'obra lingüística inèdita de Joan Palomba», dins Paolo Maninchedda (a cura de), La Sardegna e la presenza catalana nel Mediterraneo. Atti del VI congresso (III Internazionale) dell'Associazione Italiana di Studi Catalani, I, Càller: CUEC, 1998, p. 540-554, i la introducció a Joan PALOMBA, Nuova grammatica del dialetto algherese odierno, I L’Alguer: La Celere, (en premsa), i Pere CATALÀ i ROCA, op. cit., i L'aventura catalanista de "La Palmavera» (L’Alguer, 1906), L'Alguer: Edicions del Municipi, 1998, p. 205-216. 
des, fins i tot arriba a dipositar la confiança o el reconeixement en les persones o entitats que menys s'ho mereixen. ${ }^{11}$

Mentrestant, la llengua recula, és clar — ja vaig parlar en un altre lloc de les conseqüències d'una situació com aquesta en el conreu de la literatura-, ${ }^{12} \mathrm{com}$ recula en els altres confins del català, ${ }^{13}$ cada vegada més pròxims a l'àrea central. Això no obstant, i en el cas alguerès, allò que és sorprenent és que s'hagi pogut arribar fins aquí. Participa, doncs, d'aquesta resistència que caracteritza la llengua comuna, sense cap mena de dubte. Però tota resistència té un límit i és evident que a l'Alguer s'hi ha arribat. Només un canvi d'actitud radical, deia abans, permetria aturar la substitució lingüística i redreçar la situació. I la veritat és que, malgrat tot, en l'actualitat hom pot comptar amb uns quants instruments inexistents uns anys enrere. En primer lloc, un marc legal diferent: les dues lleis de tutela esmentades, del tot insuficients però que permeten una certa actuació. I l'aval donat per la Secció Filològica de l'Institut d'Estudis Catalans al Model d'àmbit restringit de l'alguerès, ${ }^{14}$ en la reunió del 12 d'abril de 2002. Això ha de possibilitar l'extensió de l'ensenyament de la llengua no només a tota l'escola primària, que des de 1994 rep, a més, el valuós suport del Centre de Recursos Pedagògics Maria Montessori, ${ }^{15}$ sinó a l'ensenyament mitjà i secundari; d'ençà del curs 1993 / 1994, la Universitat de Sàsser, la universitat més pròxima a l'Alguer, compta amb un lectorat de català. I ha de possibilitar, també, la presència normal i normalitzada del català en els mitjans de comunicació locals; presència que ara es pot veure reforçada per la recepció de televisió via satèl.lit i per la navegació per Internet, que fan que els confins ho siguin menys. No és molt, certament, és el mínim exigible. Tot

11. Cfr. A. Bover i FonT, «L'Alguer i els Països Catalans: retrobats però desconeguts», Serra d'Or, juliol-agost 1997 , p. 37-39.

12. Cfr. A. BOvER i FONT, Literatura i models ..., op. cit.

13. Sobre el retrocés del català a la frontera sud del seu domini lingüístic, per exemple, veg. Brauli Montoya, Variació i desplaçament de llengües a Elda i a Oriola durant l'Edat Moderna, Alacant: Institut d'Estudis Juan Gil-Albert, 1986, i «L'oriolà: una varietat siscentista de la llengua catalana», dins Actes del Tretzè Col-loqui Internacional de Llengua i Literatura Catalanes. París 2000, Barcelona: Publicacions de l'Abadia de Montserrat, (en premsa).

14. Cfr. Luca Scala (a cura de), Català de l'Alguer: criteris de llengua escrita. Model d'àmbit restringit de l'Alguerès. Document aprovat per l'Institut d'Estudis Catalans, Barcelona: Publicacions de l'Abadia de Montserrat, 2003. La consecució d'un instrument tan fonamental com aquest ha topat, també, amb nombroses dificultats, d'ençà de la creació de la Comissió per a la Normalització de l'Alguerès (1991), presidida pel professor Antoni M. Badia i Margarit, de la qual vaig formar part i que el blaverisme local — per dir-ho a la valenciana — va fer avortar, fins a l'aprovació i publicació d'aquest document, passant sobretot per la pacient i tenaç labor de Joan ARMANGUÉ i HERRERO, "Un registre oficial per al català de l'Alguer», dins Estudis catalans a Sardenya, Dolianova: Arxiu de Tradicions, 1999, p. 27-29, d'Andreu Bosch i Rodoreda, que va ser el primer lector de català a la Universitat de Sàsser, i de Luca Scala.

15. Cfr. Andreu Bosch i RodoredA, «El català de l'Alguer, el nou marc legal i l'escola», dins La Sardegna e la presenza catalana nel Mediterraneo ..., I, op. cit., p. 373-396, i "L'ensenyament del català a l'Alguer i la qüestió del model de llengua», dins Joan A. ARGENTER (a cura de), Jornades de la Secció Filològica de l'Institut d'Estudis Catalans a l'Alguer, BarcelonaL’Alguer: IEC/Municipi de l'Alguer, 2001, p. 55-64. 
depèn, doncs, de la voluntat. Com sempre, al capdavall. De la voluntat d'unes autoritats municipals que haurien de liderar la recuperació de la llengua, donant exemple i creant les condicions perquè la població torni a tenir confrança en el seu idioma i abandoni l'autoodi, perquè el teixit associatiu pugui ser l'expressió de les necessitats socials i no de les de determinats protagonismes nefastos, perquè les famílies aturin la substitució lingüística. De motivacions, no sembla que en faltin, ja que, com vaig dir en una altra ocasió, «l'alguerès, la llengua catalana de la ciutat, a més de ser la manifestació més important del seu patrimoni cultural, és l'element que la posa en avantatge, respecte de la resta de Sardenya, en front d'un mercat de més de deu milions d'habitants en la mateixa àrea mediterrànea de la Unió Europea». ${ }^{16}$ Dit d'una altra manera, quan es tracta d'una llengua minoritzada com la nostra, viure en els confins fa més difícil conservar-la, però només el manteniment de la llengua fa possible obtenir algun avantatge del confinament. 